\title{
Three Recalcitrant Problems of Argument Identification*
}

\author{
Michael E. Malone Northern Arizona University
}

\begin{abstract}
Logicians disagree on (1) criteria for the presence of an argument, (2) criteria for adding implicit premises and (3) criteria for linking premises. I attempt to resolve all three problems, and in the process to remove the main obstacles to teaching diagramming. The first problem is resolved by working with real discourse that students find on their own, rather than the artificial examples and problems found in logic texts; it is further reduced by examining the different $u$ ses of argument and understanding the extent to which the basic rules of diagramming are the same for the various uses. The other disagreements persist because logicians neglect to clarify the principal type of weakness we remedy by adding implicit premises and linking premises: in real discourse we do so to block substantive counterexamples, an idea correlated with that of substantive deduction, discussed by Govier, Wright and others.
\end{abstract}

Résumé: Les logiciens sont en désaccord sur les critères à employer pour (1) identifier un argument, (2) ajouter des prémisses implicites, et (3) déterminer quand des prémisses se joignent. J'essaie de résoudre ces trois problèmes et d'éliminer les difficultés principales dans l'enseignement des représentations schématiques des arguments. On résout le premier problème en employant des exemples d'arguments et de problèmes recueillis par les étudiant(e)s au lieu des exemples artificiels qui se trouvent typiquement dans les manuels de logique. On diminue davantage ces difficultés en examinant les différents usages des arguments et en constatant jusqu'à quel point les règles de schématisation s'appliquent bien à ces divers usages. Les autres désaccords persistent parce que les logiciens négligent d'identifier la faiblesse principale éliminée par l'insertion d'une prèmisse implicite: dans les entretiens véritables on les ajoute pour bloquer des contreexemples substantiels. Cette idée se relie à la déduction substantive, dont discutent Govier, Wright, et d'autres auteurs.

Keywords: Argument diagrams, convergent premises, counterexample, implicit premises, independent premises, linked premises, logic, informal logic, substantive deduction

\section{Introduction}

According to both Douglas Walton (1996, pp. 94-95) and Ralph Johnson (1996, $27-29 ; 55-6 ; 67-69)$, persistent disagreement on three issues prevents argument diagramming from becoming the universal approach to teaching informal logic. Logicians disagree (1) on how to determine whether a piece of discourse contains any reasoning at all, and on how to tell whether it contains a persuasive argument or some other type of reasoning, such as an explanation. They also disagree on (2) criteria for adding implicit premises, and (3) criteria for linking premises. I shall 
offer a reason why problem (1) persists and suggest an avenue by which it can be resolved. I shall then attempt to solve, or at least defuse, problems (2) and (3).

Note, however, that none of them concerns diagramming per se, nor do the techniques of diagramming purport to resolve them. Whether a bit of discourse contains arguments, how many (which is another way of asking whether premises are linked or independent), and whether it depends on implicit assumptions are problems of argument identification in general. Diagramming is merely one method of representation. I use diagrams in this essay, and I believe it to be good pedagogy to construct them together with students and to assign them as exercises. 'As I see it, the problem aggrevated by these disagreements lies not with diagrams per se, but with teaching the art of argument identification itself. That is a shame, because students readily acknowledge the need for such instruction.

\section{Identifying Arguments}

In the question, "Does this discourse contain an argument?" the word "argument" could mean reasoning of any kind, or an attempt at persuasion as opposed to reasoning of some other kind. I shall address the two uses of the word separately.

The primary cause of disagreement about whether discourse contains reasoning, I believe, is that logicians use trumped-up, artificial examples rather than real discourse. As I develop my line of thought in this paper I shall provide several examples from standard logic textbooks and compare them with examples taken from real discourse, most of them found by students outside of class. By "real discourse" I mean such as occurs in the classics, in textbooks and the professional literature of a field, in editorials and political debates. Real discourse has a context-an author with definite purposes, an audience with specific interests and knowledge, etc. It is by grasping how a piece of discourse is situated in its circumstances, as much as by looking for textual clues, that we see reasoning in it. Telling whether a piece of real discourse contains reasoning is seldom a recalcitrant problem. There are borderline cases, but this is hardly surprising.

Unfortunately, most logicians avoid real arguments. The attitude expressed by Moore and Parker (1995) is typical. They use the following simplistic, artificial example to introduce diagrams:

I don't think we should get Peter his own car. As a matter of fact, he is not responsible, because he doesn't even care for his things. And anyway, we don't have enough money for a car, since even now we have trouble making ends meet. Last week you yourself complained about our financial situation, and you never complain without really good reason (p. 244).

Actually, this is fairly sophisticated, as textbook examples go. But it turns out that Moore and Parker are "concerned primarily with argument evaluation rather than argument clarification, so most of the arguments we present are straightforward and unconfusing" (p. 247). It is appropriate to introduce the techniques of repre- 
sentation using an example whose content is unproblematic. But a course that never tackles examples more difficult than this will have little application to the identification of arguments in everyday discourse. Even the problems in the LSAT, all brief and contrived, are more realistic and challenging than the typical examples and problems in logic texts. Logicians gloss over the difficult issue of identification and concentrate on evaluation. Some of my remarks in this paper imply that they oversimplify the concept of evaluation as well.

In the other sense of "argument" the question asks how to distinguish an attempt at persuasion from reasoning of other kinds, such as explanations, discoveries of hidden implications, inferences to the best explanation, etc. While there are important differences between the various uses of reasoning, there are some similarities that hold generally.

(1) Reasoning of all types makes use of inferences from one or more grounds to a conclusion. In fact, essentially the same set of statements, in the same configuration, can often be put to more than one use. The Declaration of Independence declares that the colonies $d o$ declare independence. It is a moral justification-a species of explanation. But with only slight changes in the modalities it could represent the reasoning by which the colonists persuaded themselves that they ought to declare independence.

Differences of use can, however, result in more dramatic differences in diagrams. The statements we regard as law-like generalizations begin as hypotheses. The statement that air has weight (Hempel, 1966, p. 9ff.), to cite a familiar example, can be the conclusion of an argument that persuades us of its truth, and the phenomena it correctly predicts will be premises. When it attains the status of a law, it and those same phenomena can reverse roles: what was a premise becomes a conclusion and vice versa. But in spite of these differences, in each case we infer a conclusion from grounds, individually or collectively.

(2) While inferences, and hence their diagrams, can differ from one use to another, rules for diagramming inferences do not differ from one use to another. The Declaration of Independence claims, in effect, that (a) whenever people are living under a despot they have the right and the obligation to overthrow that government and set up new guards for their security, (b) the colonies have been living under a despot, and so (c) the colonies are now obliged to declare independence. The inferential relationships between these statements are the same whether they are used to justify an action or to persuade someone to take the action. Likewise, there are both similarities and differences between reasoning from a hypothesis to its test implications and later using that same hypothesis as an explanation. In the former case the hypothesis is unasserted, whereas in the latter case it is asserted. But in both cases we analyze the inferences using the same rules for diagramming and evaluating whether the grounds imply the conclusion. That reasoning has diverse uses is not an obstacle to diagramming unless some uses cannot be diagrammed or different uses must be diagrammed according to different 
$\operatorname{mon} \quad$ M., E. Malone

rules. But the rules for diagramming are the same for the various uses. Each inference consists of premises and conclusion, the premises are either linked or independent, and how one justifies linking does not differ from one use to another.

(3) Finally, the logical strength of inferences does not depend on their use. These considerations warrant the conclusion that arguments of all types can be diagrammed according to the same rules and evaluated using the same criteria of logical strength-whether the premises imply the conclusion and whether the premises are true. ${ }^{2}$

Working with real discourse should address both aspects of the first recalcitrant problem: by learning to represent the reasoning in real, messy discourse, students learn to diagram arguments, ${ }^{3}$ and the most general rules for diagramming and evaluating inferences are the same for the various uses of arguments.

Working with real discourse can help solve the other two problems as well. Drawing on criticism of real arguments, sections 2 and 3 propose a strategy for adding implicit premises and linking premises, respectively. I begin with implicit premises because (a) there is more agreement on criteria for adding them than on criteria for linking, and (b) it goes without saying that an implicit premise must be linked to the others it supports. Once we see how implicit premises support inferences it will be easier to see how in general linking premises strengthens an argument.

\section{Discovering Implicit Premises}

I shall address the topic of implicit premises in terms of three questions:

(1) What is an implicit premise?

(2) How do we know an argument has an implicit premise?

(3) How do we identify an argument's implicit premise(s)? ${ }^{4}$

There is obviously some redundancy in the questions. I address them separately to discover the point at which logicians disagree. They do not disagree on the answer to the first question. Take Scriven's (1976) account of implicit premises as a paradigm:

You can either leave the argument the way you find it, in which case a good deal of your criticism will be criticism of the inferences in it, or you can patch it up by adding some assumptions on which it is obviously depending, in which case the inferences will be pretty satisfactory, but the assumptions will now come under fire. There is no essential difference between the inferences in an incomplete argument and the missing premises in a complete argument (p. 83).

Terminology used by other logicians ranges from the vocabulary of logic to metaphors. ${ }^{5}$ But all agree that we add implicit premises to remedy invalidity.

It is not surprising, then, that they agree on the answer to the second question: we add an implicit premise because, as Ennis (1982, p. 62ff.) puts it, the argument 
has a logical gap. ${ }^{6}$ Logicians take a wrong turn, though, in their amplification of the concept of a logical gap. The type of invalidity they normally consider is that of enthymemes.' The word "enthymeme" is ambiguous. It is defined as a syllogism with a missing premise, and the word "syllogism" can mean either a formally valid argument, like a categorical syllogism or a modus ponens, or just a deductive argument with more than one premise, whether formally valid or not. In claiming that logicians consider only enthymemes, I mean arguments that would be formally valid but for a missing premise.

In a similar vein, many textbooks adopt a method for demonstrating invalidity that Copi calls a "logical analogy" (1978, p. 203ff.). Calling it "the method of counterexample," Hurley (1991, p. 53) instructs us to (1) isolate the form of the argument and (2) construct a substitution instance having true premises and a false conclusion, like this,

Since some employees are not social climbers and all vice-presidents are employees, we may conclude that some vice-presidents are not social climbers.

The form of the argument is

Some $\mathrm{E}$ are not $\mathrm{S}$, and all V are E. So Some V are not S.

With the following substitutions,

$\mathrm{E}=$ animals, $\mathrm{S}=$ mammals and $\mathrm{V}=$ dogs, we see that the resulting inference can have true premises and a false conclusion: Some animals are not mammals, and all dogs are animals. Therefore, some dogs are not mammals. ${ }^{8}$

By definition, valid arguments have no logical gaps. So adding a statement that makes an argument formally valid fills any gaps it might have had. And a logical counterexample does show that the target itself is formally invalid. But, as I shall demonstrate, these strategies are of no use in identifying implicit premises of the original argument. They are, in fact, red herrings.

In the previous section I claimed that the proper subject of informal logic is arguments that occur in real discourse - textbooks, editorials, political discussion, etc. These arguments are quite commonly put forward as conclusive. Critics also commonly purport to show that one of them is inconclusive. But I have never seen a criticism in these types of discourse in which the standard of conclusiveness was formal validity. It seems always to be what Govier labels "substantive deductive inference" ("Substantive deductive inference depends on meaning rather than on form" (1987, pp. 96-7)). ${ }^{9}$ The concept of substantive deduction has a corresponding notion, that of a substantive counterexample. Here is a simple illustration. Imagine that one of my advisees claims she can graduate next term because she will have completed 120 semester hours. Examining her transcript we discover that she has not completed all of the required major courses. 


\section{Michael E. Malone}

If we ask how one identifies a substantive counterexample like this, we can see more clearly how the formal approach misrepresents the problem. Obviously, the inference from "I will have completed 120 hours" to "I can graduate next semester" is formally invalid. It is a truism that any inference can be made formally valid by the addition of the associated conditional-in this case, "If I have completed 120 hours, then I can graduate." Since it makes the argument formally valid, it fills the logical gap. But simply adding the conditional sheds no light on its truth conditions. In addition to completing the major requirements we can easily think of others. Students must also complete liberal education courses, maintain a certain grade point average, and perhaps demonstrate competence in a foreign language. Failure to satisfy any constitutes a substantive counterexample. To return to our question, how am I able to come up with them? I draw on my knowledge of university requirements and use my imagination. Formal logic has nothing to say on this score.

There are, then, at least two problems with the formal approach to identifying and filling logical gaps. (1) While the implicit premises it identifies succeed, if true, in filling any logical gap, they shed no light on what is required to make them true and hence to fill that gap. (2) By presupposing that conclusiveness is wholly a matter of an argument's form, it construes formally invalid inferences as either incomplete or inconclusive.

Using a couple of real arguments, I want to explore further how the concept of a substantive counterexample can provide a more fruitful account of what logical gaps are and how best to identify fillers for them.

The first example occurs in a syndicated editorial:

In Arizona's Coconino and Navajo counties, Native Americans represent $29 \%$ and $51 \%$ of the population, respectively. Yet no Native American has ever been elected county judge in either county in at large elections. So in these counties there has been a denial of equal opportunity to participate in the electoral process (Will, 1995, p. 6).

This argument, too, could be treated as an enthymeme. The two premises say nothing about equal opportunity. Adding the associated conditional would remedy this, making the argument a modus ponens. The author of the editorial, however, criticizes the argument by giving two substantive counterexamples: there might be too few qualified and interested Native American candidates in these counties, or it might not be in the interest of Native Americans to have one of their own as county judge. Either possibility enables us to see that the explicit premises do not imply a denial of equal opportunity. To block the counterexamples, the argument needs a conjunction of implicit premises, one having to do with the size of the pool of qualified candidates, the other with Native Americans' beliefs about their own interests. 


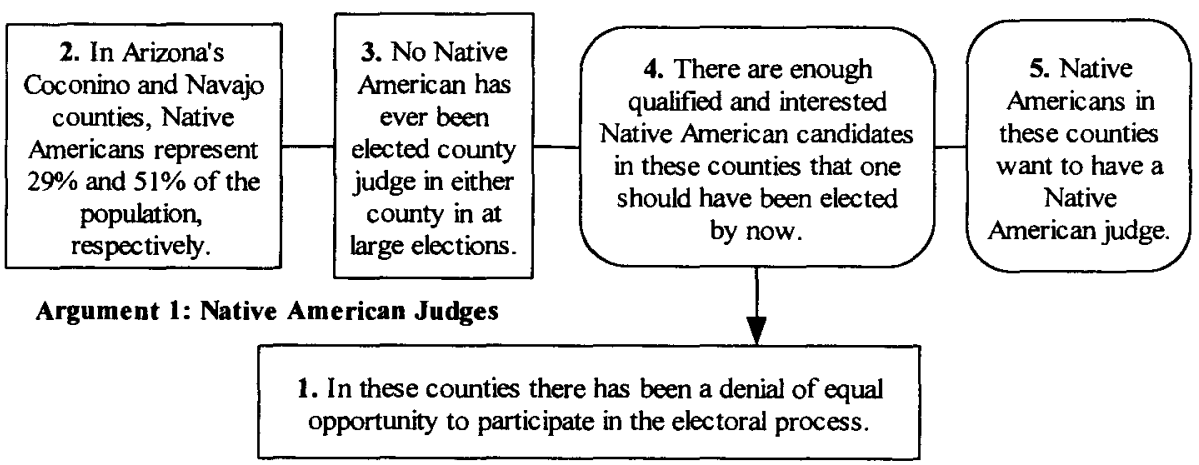

While adding the associated conditional to 2 and 3 would make the argument formally valid, if either 4 or 5 were false, the associated conditional would itself be false. And the associated conditional does not reveal the counterexamples from which the critic got 4 and 5 . How, then, did the critic do it? Taking for granted a body of knowledge regarding Native Americans living on reservations, on court jurisdictions, and on the concept of "equal opportunity," he imagined ways the argument could go wrong. There is no method for this use of imagination, and formal logic sheds no light on how to do it.

The second example comes from a geology text.

Lyell and other geologists of the nineteenth century speculated that it might be possible to determine absolute ages by using the stratigraphic record. If one measures the rate of sedimentation in the sea they argued, and if one determines the thickness of all strata, it should be possible to calculate how long it has taken for all the sediments in the stratigraphic record to accumulate (Skinner and Porter, 1992, p.163).

As stated, Lyell's argument appears to contain one premise, which is a conditional statement, and a conclusion.

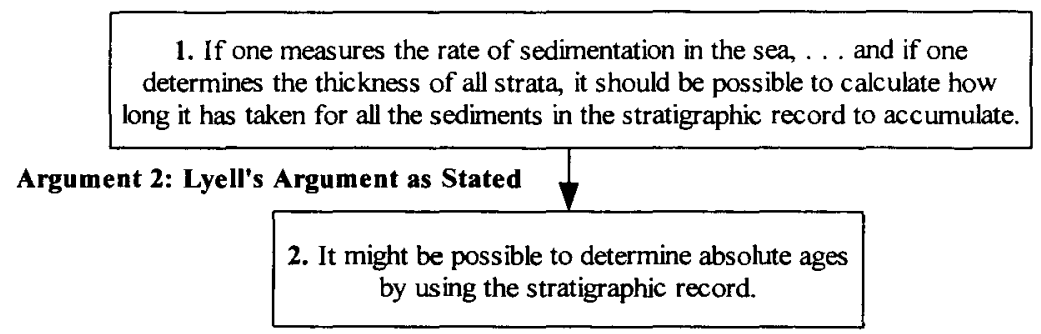

Statement 2 and the consequent of statement 1 appear to be stylistic variants. In 
that case this argument, too, could be construed as an enthymeme. We would ask whether the truth of 1 gives sufficient grounds to assert 2. If they could measure the rate of sedimentation in the sea, and if they could determine the thickness of all strata, then they might be able to calculate how long it has taken for the strata to accumulate. To make Lyell's inference formally valid we must add implicit premises that complete the modus ponens.

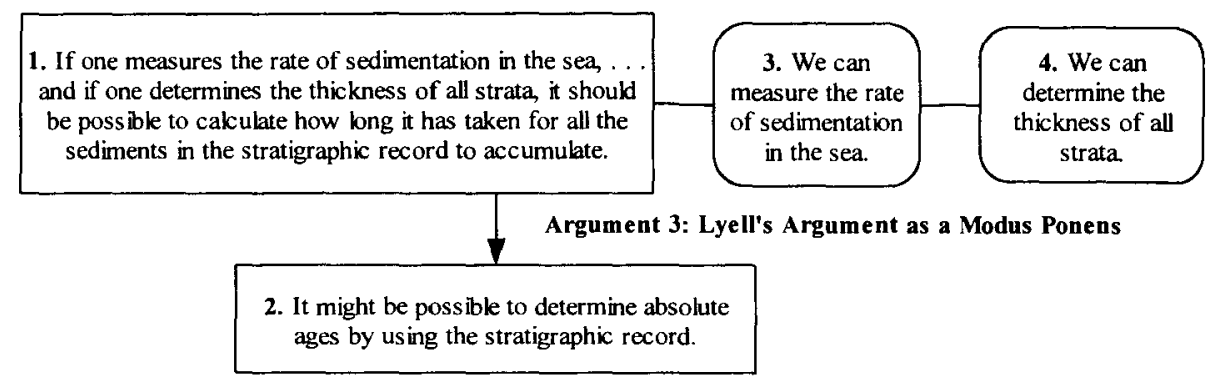

But these are not the implicit premises the authors give.

Two assumptions must be correct for the method to work. First, it must be assumed that the rate of sedimentation has been constant throughout geologic time. Second, it must be assumed that all strata are conformable, meaning they have been deposited layer after layer without interruption (ibid.).

They seem to be saying that even if 3 and 4 were true, there are still two logical gaps, which would be filled by adding 5 and 6 to the antecedent of 1 :

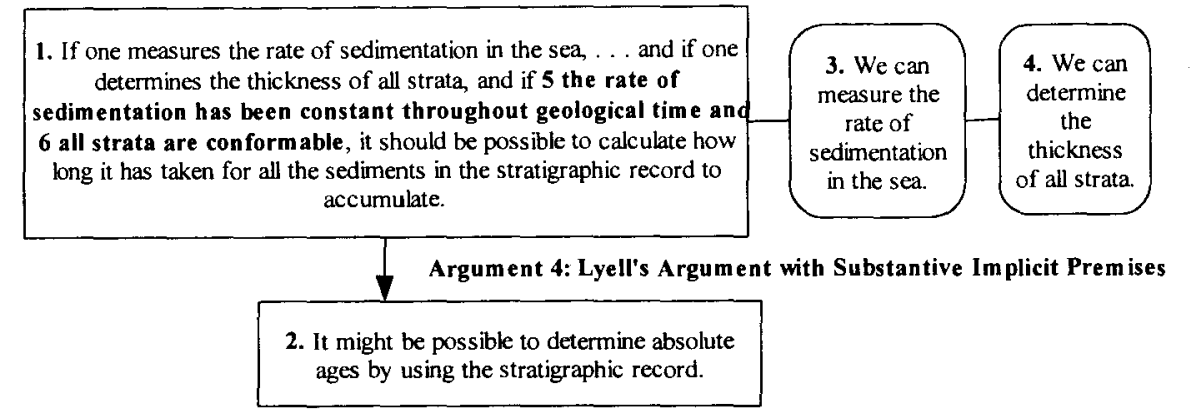

Attending to the form of the original argument would not reveal that it needs 5 and 6. (The authors argue for the counterexamples that generated the implicit premises. That is, they argue that the implicit premises are false. Climate can change the rate of sedimentation and various processes can result in nonconformities.) 
These two examples typify, I believe, the issues that arise in the identification of implicit premises in real arguments. Critics in both cases added implicit premises to block substantive counterexamples, which would not have surfaced for a critic whose paradigm of arguments with implicit premises was enthymemes. Critics discovered them by reflecting on what they knew about the subject matter at issue and imagining possibilities.

As I have discussed the topic of implicit premises, there is a redundancy in questions 2 and 3 that others have not noticed.

Question 2: How do we know that an argument has an implicit premise

(i.e., a logical gap)?

The formalist answers that it has an implicit premise if and only if it is formally invalid. I answer that it has an implicit premise if and only if there are substantive counterexamples to it.

Question 3: How do we identify an argument's implicit premise(s)?

The formalist answers that we add a statement to make it formally valid. My answer to 2 implies an answer to 3: Describe a circumstance that blocks the counterexample(s).

My examples of Native American judges and the stratigraphic record illustrate how the answer to 3 is implicit in the answer to 2 . Govier, however, sees two separate problems:

One problem about missing premises is to apply a theory of argument and to interpret a discourse and generate the judgment that there is an argument there with a missing premise. Another is, given different candidate statements which would all fill the identified gap, to select one of them as the most appropriate gap filler (1987, p. 95).

Whether there is ultimately a difference between her view and mine depends upon what she means by "theory of argument." If she means a taxonomy of uses of argument, such as I listed in the previous section, then we may agree. But I would ask why she believes there are two separate phases in the identification process. If she means instead a taxonomy of formal types of argument-syllogistic, sentential, quantificational, etc., then she appears to ignore the possibility she raised of substantive deduction and to buy into the formalist's view that we take enthymemes as our model for identifying missing premises. Two of her examples elsewhere on the same page are of the latter type rather than the former. Her third example, though, is inference to the best explanation, which is not so obviously a formal matter.

On my view, the finding of substantive counterexamples, and corresponding implicit premises, is entirely ad hoc. We do not begin with preconceptions of what a good argument of a certain formal type should contain and then interpret the argument we are analyzing as being of that type. Rather, we identify explicit premises and conclusions and then: 
1. Take the explicit premises together as a possibility-a way things could be.

2. Add some detail that implies a statement contrary to the argument's conclusion.

But what makes a substantive counterexample real (i.e., worth taking seriously)?

3. The added detail is drawn from the subject matter of the argument, rather than from some altogether different subject matter, as Hurley describes.

4. The added detail is a possibility that deserves to be taken seriously (rather than being science fiction, or what logicians often call a mere "logical possibility").

It is not always a straightforward matter to determine whether a counterexample deserves serious consideration. It seems obvious that those we discussed in connection with the Native American Judges and Stratigraphic Record arguments satisfy both 3 and 4 . In contrast, Laudan and Leplin have written that it should always be possible to think of evidence on which two rival scientific theories would differ, and hence that empirically equivalent theories are at least quite rare, and perhaps even impossible. Kukla (1993, pp. 8-16) objects that nature might operate in accordance with one set of laws (Newtonian, say) when we are observing and another set (Aristotelian) when we are not. Thus, when we are observing the earth goes around the sun and when we are not observing the sun goes around the earth. This could not be taken seriously. For one thing there is a problem of ambiguity of reference. To whom does "we" refer? Astronomers? All astronomers, or only those who are awake and observing at the moment? If some are awake and making observations, but others are asleep, which laws are supposed to be in effect? The only way to resolve the ambiguity is to interpret "we" solipsistically. But the activities of science presuppose a community. For another thing, there is the problem of making sense of the switch that is implied. While I am asleep, the earth is at rest. When I awaken the earth goes instantaneously from a state of rest to traveling at some 67,000 miles an hour around the sun, while rotating at 1,000 miles an hour - and I do not notice it! As we try to flesh out this counterexample, the necessary details do not go together cogently.

Compare Kukla's counterexample with another that is also not worth serious consideration. Mike Donn (1990) outlines a method for identifying implicit premises much like the one I advocate. Essential steps in the method are:

1. Ask yourself "Is there a way (a scenario) in which I could accept the premise(s) of the argument, while still denying the conclusion?"...3. Look for [and 4. underline] the part in your scenario which is not present in the original argument... 5. Negate the underlined part. That will be a missing premise (pp. 160-1).

He illustrates the method with the following argument: 


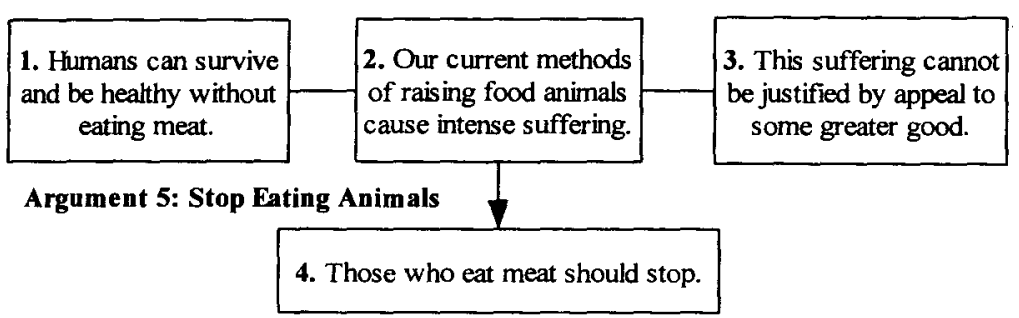

Donn adds an implicit premise to block a counterexample related to premise 1:

Despite the fact that humans can survive and be healthy without eating meat, what if there were other, more important considerations which would dictate that even though we do not need meat for our health or survival, we should, nonetheless, still eat meat? What I had in mind was the following logically possible scenario.... Suppose we came to find out that for reasons we do not understand, unless we continue to slaughter and eat food animals exactly as we do now, these animals would emit a toxic substance from their bodies that would wipe out all life on earth (including the lives of animals). Somehow our digestive system neutralizes this potentially lethal poison (pp. 163-4).

My strategy for adding implicit premises is motivated by a concern that we should restrict our discussion to those objections that raise real problems. A premise that negates a preposterous statement plays no role in the strength of the argument. Donn's choice of a missing premise betrays that he knows this. He adds a statement far more general than the negation of his science fiction "logical possibility"- the statement that the eating of food animals cannot be warranted on the basis of other considerations. Whether the argument needs that implicit premise depends on whether there are such considerations. He has so far not given any that must be taken seriously.

Discussion of cases like Kukla's and Donn's reminds us that we determine whether something is possible on the basis of our knowledge of the subject matter at issue. Most people could see, after a little discussion, that we cannot make sense of Kukla's counterexample to the Laudan/Leplin thesis. But the appreciation of much reasoning requires knowledge not everyone has. Not everyone knows whether the rate of sedimentation could have changed, or whether Native Americans want a Native American county judge. The more we know about the subject matter of an argument, the more straightforward the decision as to whether a putative counterexample is worth serious consideration, and hence whether the argument needs an implicit premise. So the idea that one can determine the logical 
strength of an argument without knowing anything about the world is flawed.

Most logicians agree on answers to the first two questions about implicit premises. The disagreement to which Walton and Johnson allude surfaces in answers to question 3: How do we identify an argument's implicit premise(s)? I shall illustrate the disagreements with just one case, which is both typical and easy to resolve given my criterion. Plumer (1999) takes Norris and Ennis (1989) to task for claiming that, "Although it is tempting to think that certain [unstated] assumptions are logically necessary for an argument or position, they are not. So do not ask for them...no significant assumptions are logically necessarily made" (pp. 122-3). Plumer responds that:

Numerous writers of introductory logic texts, as well as various highly visible standardized tests, presume without giving much (or any) justification that the Norris-Ennis view is wrong; the presumption is that many arguments have (unstated) significant necessary assumptions and that readers and test takers can reasonably be expected to identify such assumptions (p. 41).

Plumer is obviously correct that we have these presumptions. Questions like the following abound in the Kaplan practice tests for the LSAT: "The author of the argument above assumes that...", "Which of the following, if true, most helps to explain the unexpected results noted in the passage?", "Which of the following is the main point at issue between $X$ and Y?", and "The author's conclusion is based on which of the following assumptions?" Ennis is the one who gave us the expression "logical gaps." How can one hold that some arguments have logical gaps and at the same time hold that arguments do not have necessary assumptions?

Ennis's account of identifying gap fillers contains a clue. A statement is needed in an argument, he claims, if it satisfies three criteria: fidelity, contributing to gap filling, and plausibility. He says that a gap is filled when one can infer without any question a conclusion... from its support. What eventually leads him (and Norris) to claim that there are no necessary assumptions seems to be their recognition that more than one statement, or set of statements, could satisfy the italicized criterion in the previous sentence. If more than one statement could do the job, then no particular one is necessary. But there is an unfortunate logical shift in the way Ennis formulated his criterion. He meant to provide a criterion for judging that a statement is necessary for an argument's validity: the argument is valid only if it includes the statement. But his formulation of the criterion states the converse: if it includes the statement, it is valid. And there is always more than one way to make an argument valid. Johnson (1996, p. 68) discusses an example that originates with Scriven: "She's a redhead, so she's probably quick-tempered." Scriven chooses "Most redheaded women are quick-tempered" to fill the gap. Johnson claims that "Most redheads are quick-tempered" would also fill the gap. So would "All redheads are quick-tempered" and "All women are quick-tempered."

In light of the fact that more than one statement could fill a gap, Norris and Ennis advise the writers of multiple-choice questions in standardized tests to be 
very careful in how they formulate questions about an argument's assumptions. Either they should include among the answers only one that could fill the gap, or they should ask which assumption the author of the argument is more likely to be making, or which one gives the most support to the argument rather than asking which one is necessary. They do not deny, as Plumer's essay assumes, that arguments can have gaps.

A concise statement of the strategy I offer for identifying implicit premises is this:

Add the implicit premise that best blocks a real counterexample-a

possibility that deserves to be taken seriously.

This strategy has us focus on the most serious weakness in an argument and the most reasonable way to defend it from that weakness. Thus, it will go a long way toward eliminating the problem of multiple gap-fillers. The implicit premise will commonly be a statement that negates the counterexample. Thus, if the counterexample is that the rate of sedimentation has not been constant throughout geological history, the implicit premise is that it has been constant. If the detail is that the interests of Native Americans are not served by having one of their own people as a county judge, then the implicit premise is that their interests are served. Resolution of remaining disagreements should focus on the counterexample rather than appealing to intuitions of the strength of the argument.

\section{Linking Premises to Block Counterexamples}

Asking whether premises are linked or independent ${ }^{10}$ is just another way of asking whether discourse contains one argument, or more than one, for a conclusion. There seem to be paradigms of each. The example from Moore and Parker cited in my introductory remarks contains the following statements: (1) "We should not get Peter his own car," (2) "Peter is not responsible," (3) "We don't have enough money for a car," (4)"Last week you complained yourself about our financial situation," and (5) "You never complain without a reason" (244). It would surprise no one that the authors diagram them as follows:

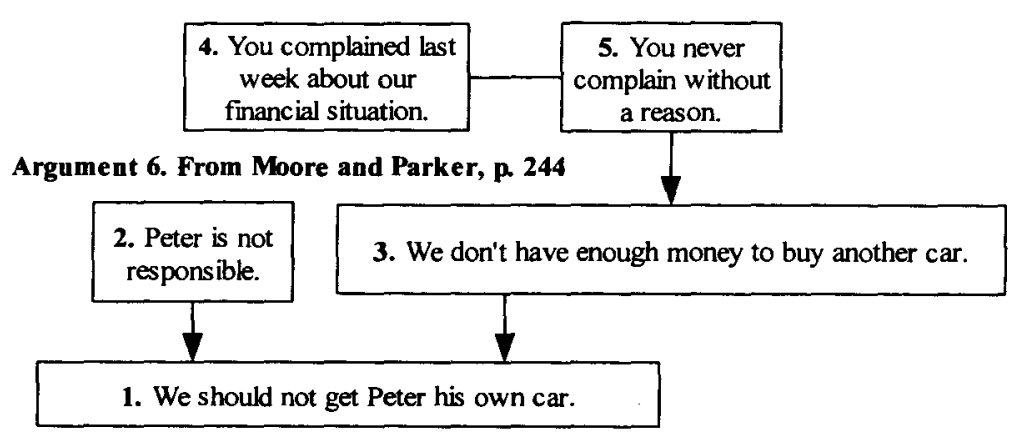


Thus the criteria for applying the distinction to paradigms like this seem clear and usable. Moreover, there is much more uniformity in the terminology logicians use to explain the concept of linked premises than in their explanations of implicit premises. They write:

Premises are linked when each is helped by the other(s): each needs the other to support the conclusion (Thomas, 1981, p. 51-2).

Linked premises function together to give support to the conclusion (Walton, 1996, p. 85).

Linked premises support the conclusion through the mediation of each other: they work "cooperatively" rather than "independently" (Copi and Cohen, 1990, p. 20).

Premises are linked when, taken separately, they provide little or no support for a conclusion, but taken together they do provide support" (Hurley, 1991, p. 59).

The expression "support the conclusion" is the focal point of each definition. Given this uniformity, and the existence of paradigms like argument 6, we might expect general agreement in judgment about whether to link sets of premises. But that is not the case.

Freeman claims that the concept of logical support common to these definitions and the downward-pointing arrow they presuppose are highly ambiguous. The concept of support could mean anything from "gives some evidence for," or "is relevant to," to "gives good or sufficient evidence for." It could even mean "implies" or "deductively entails," although, he adds, most informal logicians insist on reserving those terms for formally valid inferences. The significance of the arrow could vary in all of the same ways, he writes, from "is a reason for" to "therefore" (Freeman, 1991, p. 9ff). Without clarification of what it means for premises to support one another, we are left wondering how to justify our decision in practice to link premises.

Freeman is right that there are problems regarding the concept of logical support, but not the problems he mentions. The problem with the concept of support has to do with the standards we are to use in evaluating the argument. But evaluation and identification are intertwined. As we saw in the previous section, preliminary evaluation is needed to identify implicit premises. It is needed as well in deciding whether premises are linked or independent. But the devices of diagramming - the link and the arrow - have no significance so far as the strength of the argument is concerned. They merely indicate which are the reasons, which conclusion is inferred from them, and whether reasons are parts of the same argument or different arguments.

Walton, too, claims there is ambiguity in the concept of support. He distinguishes five different tests of adequacy of support. The first four are generated from possible combinations of positions on two issues. First, need the reader actually know that one of the premises is false or may he merely suspend belief in 
it? Second, should reader judge that, without a certain premise, the remaining one(s) provides no support or merely insufficient support for the conclusion? Thus, there is the "known to be false"/"no support" test, the "suspension of belief'/"no support" test, and so on. (1996, Chapters 4 and 5, contain ample evidence that each of the four has had its advocates.) The fifth test originates with Thomas, who defines a linked argument as one " that involves several reasons, each of which is helped by the others to support the conclusion.' This is taken by Thomas to mean that the addition of one premise to the other makes the argument stronger than it was before" (1996, p. 125). Thomas's definition replaces the expression "supports the conclusion" with the expression "makes the argument stronger," thereby replacing the problem of ambiguity with a problem of vagueness.

Whether deliberately or not, logicians sometimes avoid these problems by illustrating linked premises with formally valid syllogisms. Kelley (1998, pp. 94-95) gives an argument from Ronald Reagan that could readily be translated into a hypothetical syllogism:

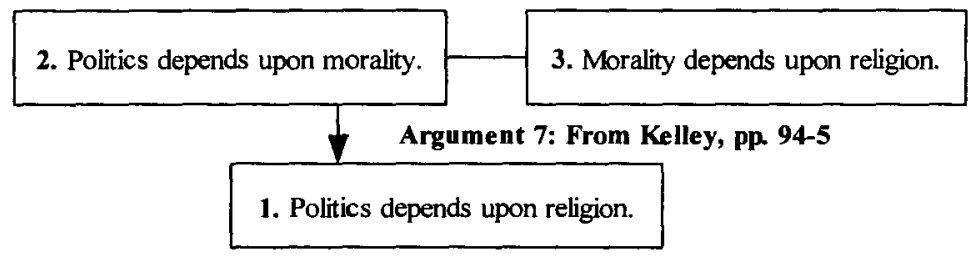

An example of Copi and Cohen's (in Walton, 1996, p.110) would be simple to translate into predicate logic:

2. If an action promotes the best interests of everyone concerned, and violates no one's rights, then that action is morally acceptable.
3. In at least some cases, active euthanasia promotes the best interests of everyone concerned and violates no one's rights.

Argument 8: From Copi and Cohen, in Walton, p. 110

1. In at least some cases, active euthanasia is morally acceptable.

But this is misleading! It is unproblematic that the premises in simple, formally valid arguments like these are linked, and for more complicated ones we already have techniques of formal logic to shore up our intuitions that the premises must be linked. In fact it is tempting to conclude that since we already have the techniques of formal logic for representing and evaluating formally valid arguments, 
we don't need diagrams for them. But the conclusion that diagrams are useless and misleading is a non sequitur. Most real arguments are complex, and diagrams represent arguments with intermediate conclusions, even formally valid ones, more perspicuously than the alternative method.

Illustrating linked premises with syllogisms misleads in another way. It is because logicians disagree about even the simplest formally invalid arguments that they find the linked-independent distinction problematic. Walton gives a classic example of Beardsley and Thomas diagramming the same premises in conflicting ways (1996):

Beardsley's Diagram

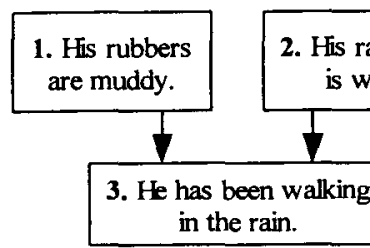

Thomas's Diagram

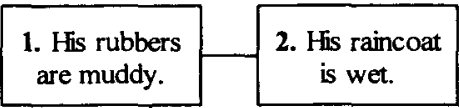

3. He has been walking in the rain.

It might seem that there is disagreement about even the simplest of cases because we do not know what standard of logical strength we ought to apply to them. If the standard is "gives some reason to believe", then we have as much reason to accept Beardsley's diagram as Thomas's. But if conclusiveness is the standard, Thomas's seems better.

Disagreements like this persist, I believe, because logicians have given little thought to how the concepts of support and strength can be applied to arguments. We use the concept of strength in two different ways. When we say that someone got stronger, there might be no implication of an antecedent infirmity. To say that Schwarzenegger became stronger by lifting weights does not imply that he began as the proverbial ninety-eight pound weakling. But sometimes in saying that someone became stronger we do imply that there was an antecedent weakness, as in regaining one's strength following surgery or an illness. In the former use of the word, there are typically incremental criteria for an increase in strength: Arnold can lift ten more pounds today than he could yesterday. In the latter use, too, there can be an incremental standard of strength. The patient might walk a little further each day. But to have a clear conception of the strength involved there is always more to be told: what was the source and nature of the weakness, an illness, a surgery, a broken bone, an accident? What we understand in these cases by "getting stronger" is always relative to the nature and source of the weakness.

"Support" has both uses, too. When I notify the IRS that I support my son by paying rent and tuition, I do not imply that he would be infirm without it. But when 
the architect says he included pillars to support the deck, or added electrical circuits to support the room we added, he implies that without these supports, the house would have specific weaknesses. What "support" means is determined by the weakness at issue.

When logicians use the concepts of strength and support in relation to arguments, they fail to distinguish these two different ways of using the words. Walton's two-chapter discussion of linked and convergent premises is filled with remarks that some specific argument is weaker if the premises are not linked. But there is never a mention of what the specific weakness might be. By never identifying the weakness to be prevented by linking, logicians opt de facto for the former use of the words. This will not do. There is a metrical criterion that a bodybuilder is getting stronger. To be sure, some arguments are like this-inductive ones. But the real arguments we take to be conclusive are not inductive. It is unclear what it could mean to say they became incrementally stronger.

Yanal (1991) addresses the problems of ambiguity and vagueness by construing informal arguments as inductive arguments. His criterion requires that we distinguish two ways in which the probability of premises can affect the probability of their conclusions:

The probability of the conclusion of an argument with independent premises is the ordinary sum of the probability of each premise. The probability of the conclusion of an argument with dependent premises is not the ordinary sum of the probability of each premise. I also like to put it this way: The probability of conclusions from arguments whose premises are dependent jumps beyond the ordinary sum of these premises (p. 140).

This proposal remedies the problem only if we can objectively assign probabilities to conclusions given their premises. ${ }^{11}$ His own example of independent premises illustrates, though, that in most cases either we would not know how to assign a probability to a premise, or else that the probability they confer on the conclusion is not the issue: "Smoking in this building is punishable by a fine. Besides, smoking increases your risk of heart attack. Therefore, it's against your self-interest to light up here" (1991, p. 137).

There are several problems with this example. The first premise is not a matter of probability. Either smoking is punishable or it isn't. There is, of course, the question of whether one will be caught, but a statement about that is an implicit premise rather than an interpretation of the original. The second premise also is not a matter of probability. How much smoking increases the risk converts to a statement about probabilities. But that it increases the risk is a fact! The example is odd in other respects, too. The word "here" at the end of the conclusion refers to "in this building" in the first sentence. But what does it refer to in the second? Finally, if someone were really to use this argument, it would purport to be conclusive rather than a matter of probability. As a solution to the vagueness of the concept of logical strength, Yanal's criterion makes matters worse. 
Some of the arguments Yanal and his critic, Conway, use to make their cases are trumped-up specifically for the purpose of discussing how to combine probabilities. Conway writes of two sharpshooters who have been hired to kill him. One hits $80 \%$ of his targets and the other hits $90 \%$ of hers. The issue is how to calculate the probability that he will get hit. Problems of this kind have little relevance for the proper subject matter of informal logic-arguments we encounter in everyday life.

I believe the second way of using "strength" and "support" is more appropriate to identification and evaluation of arguments, formal or informal. When we ask whether it would strengthen an inference or support a conclusion to link premises, we should answer by citing the precise weakness if the premises were not linked. In other words,

Link one premise, $B$, to another, $A$, when the inference from $A$ itself to the conclusion is subject to counterexamples blocked by $B$, and viceversa.

Consider an example that purports to be conclusive but not formally valid.

Regarding your all-too-positive section on tattoos in "Dos \& Don'ts," I cannot say this loudly enough: Buyer beware. Tattoos are serious and so are the diseases they may cause. In Arizona, tattoo parlors are not regulated or given any type of health inspection (Hendrickson, 1995, p. 32).

We can give a counterexample to the inference from either premise by itself. If there were no danger of infection, there would be no need of health inspections. If tattoo parlors were (reliably) inspected, we would worry less about the possibility of infections. Linking the premises strengthens the argument by eliminating counterexamples.

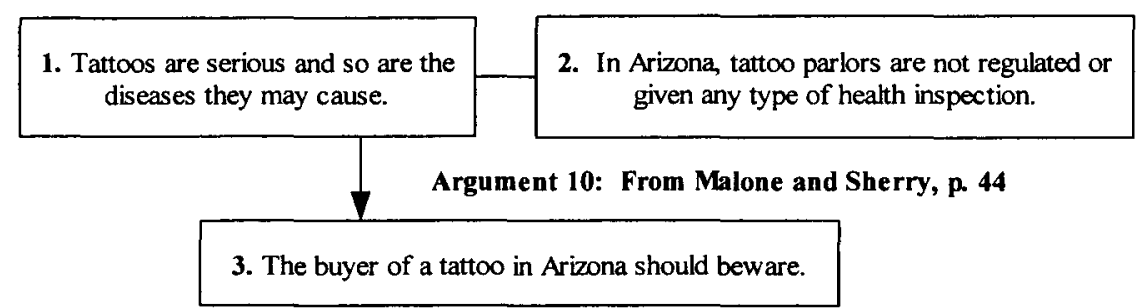

The same rationale justifies linking the explicit premises in the "Stratigraphic Record" and "Native American Judges" arguments discussed in the preceding section. If we could only measure the rate of sedimentation, but not the thickness of strata, then we could not calculate the absolute age of the earth, and vice versa. If Native Americans represented a smaller percentage of the population of those counties, or if a Native American had previously been elected county judge, the issue of denial of opportunity would not arise. 
Adoption of my criterion enables us to defend our decision to link premises by citing a specific weakness it prevents, rather than by merely appealing to people's intuitions about whether linking them strengthens the argument. Among other virtues, this enables us to settle disputed cases, and to change the diagrams of some settled cases. We can, for example, settle the disagreement between Beardsley and Thomas mentioned in argument 9. But note that one reason for the disagreement is the lack of a context. It is as if the sentences themselves are supposed to tell us what to do. My suggestion that we think in terms of counterexamples is tantamount to conjuring up a context. Is there a conceivable situation in which a person could have muddy rubbers who hadn't been walking in the rain? He could have just returned from a burial service at a cemetery where he knew there would be melting snow. Perhaps his plumbing had frozen and then thawed, and he had been cleaning up his flooded yard. Likewise a person's raincoat could be wet even though he had not been walking in the rain. He could have been engaged in a water fight with garden hoses, or dodging sprinklers as he did chores on a golf course. Linking the premises strengthens the argument by blocking counterexamples like these.

I have yet to see premises others have linked that I regard as independent. But instances of the converse are fairly common. Copi and Cohen give an example by Michael Dukakis (discussed in Walton, 1996, p. 88):

I've opposed the death penalty all of my life. I don't see any evidence that it is a deterrent and I think there are better and more effective ways to deal with violent crime.

The passage itself needs some cleaning up. If it is meant as Dukakis's persuasive argument, the conclusion should be something like "The death penalty should be abolished," and we'd make corresponding changes in the premises. Copi and Cohen would diagram it:

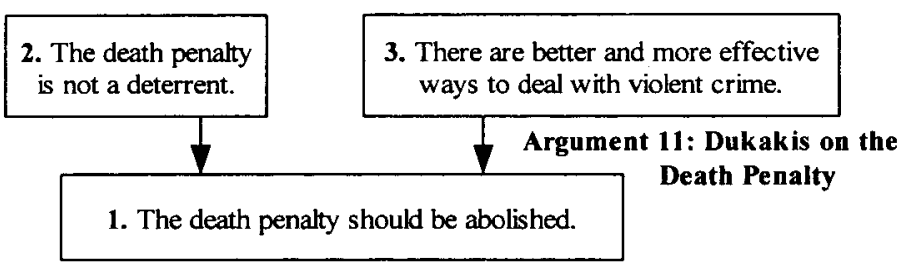

There are counterexamples to the inference from each of these premises. To the inference from 2 we could object that the death penalty makes us safer by removing a convicted murderer from society. Premise 3 says that that there are less problematic ways of doing that. To the inference from 3 we could object that the death penalty is a sign to other potential murderers that we will be harsh with them. According to statement 2 , the death penalty does not accomplish our intended goal in doing so. Thus we link the premises. 


\section{Michael E. Malone}

Perhaps, though, my strategy accomplishes more than I intend, and eliminates the category of independent arguments altogether. If so, there is something wrong with it, since surely people sometimes offer more than one argument for a conclusion. Not only does it allow for independent arguments, it is more in the spirit of what we understand by "independence" than its rivals. If one premise, A, does not block a counterexample to an inference from another premise, B, then the truth of $A$ is irrelevant to the inference from $B$. They are premises of separate arguments. If $A$ and $B$ block counterexamples to the inference from the other alone, then they are parts of the same argument. Consider a pair of arguments (Arizona Secretary of State, 1992) opposing a change in the method of capital punishment to lethal injection.

[We should not change to lethal injection because] execution by cyanide gas is not cruel and unusual punishment. Condemned murderers do not deserve painless deaths.

[We should not change to lethal injection] because there is no humane way to execute another person. Changing the method of executing condemned prisoners from lethal gas to injection simply glosses over the inherent problems with state-sanctioned executions (A rizona Secretary of State, 1992, p. 20).

On my criterion, the main arguments are independent:

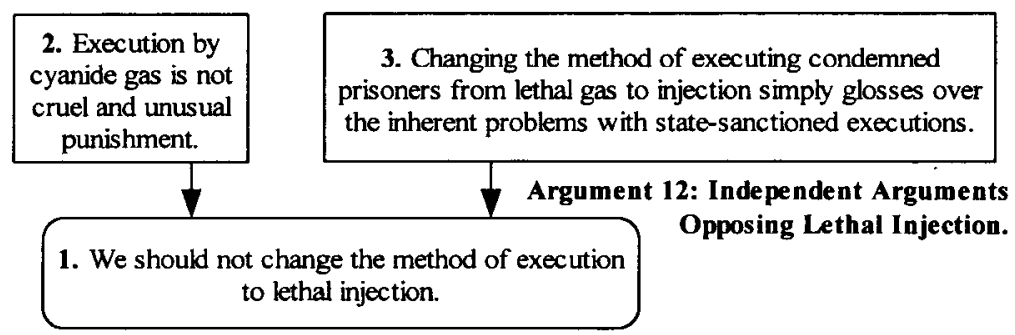

To see why statements 2 and 3 are independent reasons, we ask whether either blocks a counterexample to the inference from the other. In fact, 3 presupposes that there are inherent problems with state-sanctioned executions, and the negation of that presupposition is an implicit premise in the inference from 2 to 1 . Thus, far from supporting each other, neither premise would be accepted by a person who argues from the other. So they are independent.

Independent arguments can also occur with premises of different logical types. We sometimes argue for something on both moral and prudential grounds. A favorite editorial (The New York Times, 1994, p. A26), too lengthy to quote in full, argues that Mr. Cortines, Chancellor of New York City's public schools, should enforce the mandate of the previous chancellor that students must take three years of 
substantive math and science courses to graduate from the city's high schools. The author argues that (1) the more substantive courses would help college-bound students develop critical thinking and analytical skills and help all graduates compete in an increasingly demanding job market, and (2) weak standards cheat both the students and the city that depends on their talents. An objection to the inference from (1) would be couched in terms of a cost-benefit analysis. The benefits of implementing the standards could be outweighed by the inconvenience and difficulty of implementing the standards. The implicit premise blocking this counterexample is that the instrumental value to the students and the city outweighs the inconvenience. The moral obligation implicit in (2) is not relevant to the question of a cost-benefit comparison. Conversely, counterexamples to the inference from (2) would, it seems, have to be couched not in terms of inconvenience but of a claim that the city simply cannot implement the more substantive courses. Inconvenience does not release us from a moral obligation. Thus (1) and (2) are independent premises.

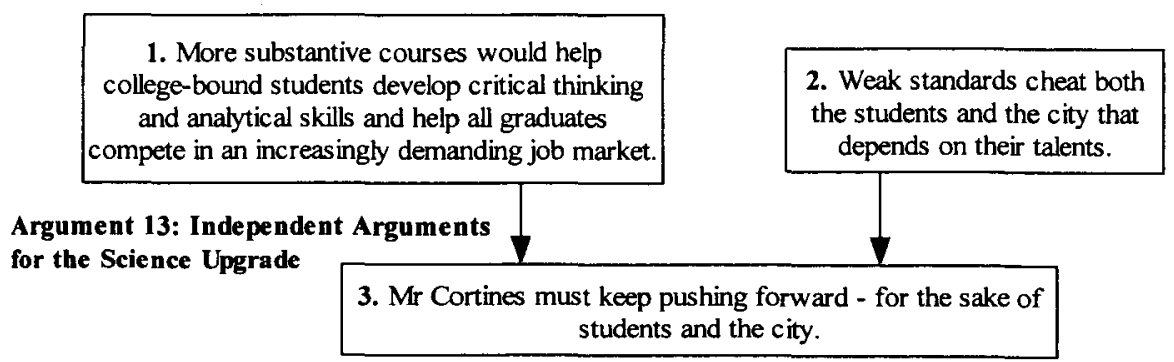

Arguments 12 and 13 illustrate that my criterion does not eliminate the class of independent premises altogether.

There are two principal advantages of giving counterexamples as a way to add implicit premises or justify linking premises. I have already mentioned that it gives us a way to settle disagreements, to justify our decisions objectively, by pointing to specific weaknesses the arguments would otherwise have. It also makes use of the most common way in which we criticize the logical weaknesses of arguments in real discourse, and of the way in which authors of real discourse criticize arguments. It is so common, in fact, that students come to their first logic class with intuitions of how to do it.

\section{Summary}

The three problems are strands of a Gordian Knot. The first step toward severing it is to cease trying to solve the problems in terms of the concepts of formal logic 


\section{Michael E. Malone}

and the contrived, artificial examples that are its stock in trade. Instead we should work with real discourse. Our understanding of context, including the intentions of the author and the circumstances of the audience, minimizes problems of telling whether the discourse contains reasoning at all. And, whereas differences between uses of argument can result in the same statements' being used in quite different ways, the most general rules for diagramming arguments are the same for all of the uses. Concentration on real arguments also brings into focus that the standard of conclusiveness appropriate to them is most often substantive rather than formal. We identify logical weaknesses in real arguments by giving counterexamples that draw on the subject matter of the argument. The idea that we can block these substantive counterexamples, both by adding implicit premises and by linking premises, gives us the solution to the other two problems.

\section{Endnotes}

* Thanks to David Sherry and Peter Kosso for suggestions.

1 My diagrams were done with Smart Draw 6, available at www.SmartDraw.com. I enclose explicit statements in square-cornered boxes, and implicit statements in round-cornered ones. Horizontal lines between boxes represent linked premises, i.e., to be taken as premises in a single argument, and vertical arrows represent inferences by pointing to the conclusion. Arrows could originate from any one of a set of linked premises, or from a link between them. Numbers are for reference only, and have no logical significance.

2 The reader may wonder how we can use the same criteria of validity for explanations as for persuasive arguments. Demonstrations of invalidity show that the conclusion could be false even if the premises were true, but we take the conclusion of an explanation to be true. Sherry and I proposed a solution to this in "Diagramming Criticisms of Explanations," at the Central Division Meetings, American Philosophical Association, 1999, also discussed in Malone and Sherry (1998, pp. 201-5). Any explanation implies a counterfactual conditional. If we can show that the counterfactual conditional is false, we have shown that the given explanans does not imply the explanandum. For example, a student tells us that he can't turn in his paper today because his printer is broken. According to his explanation, if his printer hadn't broken, he would have had his paper today. We criticize the explanation by falsifying the counterfactual conditional: Even if his printer weren't broken, he wouldn't have his paper today, assuming he has not finished writing his paper.

${ }^{3}$ Copi and Burgess-Jackson (1996, p. 31), recommend attempting to construct a diagram as a strategy for deciding whether a piece of discourse contains an argument.

4 That there is a distinction between 2 and 3 is suggested by Trudy Govier (1987, p. 95).

s Compare Copi (1978, p. 242), Robert Fogelin (1982, p. 125), Robert Ennis (1982, p. 62ff), Govier (1987, p. 92), and Gilbert Plumer (1999, pp. 43-4).

${ }^{6}$ Ennis (1982, pp. 63-66), distinguishes implicit assumptions that are used from those that are needed. On his analysis, a used assumption amounts to a belief of the author that might shed 
light on why she reasons as she does (an assumption of the arguer), whereas a needed assumption is a part of the reasoning itself - it fills what he describes as a "logical gap" (an assumption of the argument). Corresponding to this distinction is a disagreement, Johnson writes (1996, pp. 67-8), between Scriven and Thomas on the aims of logical analysis. For Thomas, since the aim is to arrive at the truth, regardless of the actual beliefs of the author, we should add implicit premises that best fill the gaps, whether the author believes them or not. For Scriven the aim is to get clear on the intent of the author, which would caution us against adding premises we have no reason to think the author accepts. I presume that Ennis, Scriven and Thomas all agree that we add implicit premises that are both needed and used. They might disagree on what to do with assumptions that are used but not needed, or vice versa. I am trying to remedy confusion in the standard accounts of what a logical gap itself is, and how best to fill it. This issue is logically prior to those on which Scriven and Thomas disagree.

${ }^{7}$ In addition to most of the works cited in notes 5 and 6, see Lee Rowen (1984, p. 9) and Donald Hatcher (1999, p. 78), who argue explicitly that we should teach students to identify implicit premises by introducing them to enthymemes, where it will be relatively obvious to them what's missing.

${ }^{8}$ Tarski introduces this method in Logic, Semantics, Metamathematics, ed. Woodger (1956), pp. 408-420, first published in 1936.

${ }^{9} \mathrm{~A}$ reviewer for this journal wondered why I emphasize that not all deductive arguments are formally valid, claiming, "We all knew it before we read the paper." In the first place, it is not true that everyone "knows" it. Remarks like the following are very common: "Logicians have traditionally distinguished between two types of reasoning - deductive reasoning and inductive reasoning. Deductive inferences are valid by virtue of their forms.... Inductive inferences, on the other hand, such as interpolation of a point on a graph, go beyond the given data and there is no criterion for assessing their validity," Wason and Johnson-Laird (1968, p. 11). The prejudice persists even today. "You need not know anything special about the world to know whether an argument is valid or invalid. But you need to know some facts to know whether a premise is true or false," Ian Hacking $(2001$, p. 7 ). To allow that the concept of a substantively deductive argument is even intelligible requires that some assessments of validity depend on knowledge of the subject matter. In the second place, and more to the point of my argument, even if it were true that logicians in general accept substantive validity as a possibility, it never enters their discussions of how to identify implicit premises or justify linking premises.

${ }^{10}$ Authors mark this distinction with different words and expressions. For example, they use "convergent" or "multiple" as synonyms of "independent", and "dependent" and "coordinatively compound" as synonyms of "linked".

$"$ Yanal's account is ambiguous. The first sentence seems to say that we must determine the probability of each of the premises in order to determine how they affect the probability of the conclusion, together and separately. The last sentence, however, appears to apply to the probability of the inference rather than the premises. His and Conway's example does not resolve this ambiguity, since its premises make probability claims. But the premises of most arguments do not make probability claims.

\section{References}

Arizona Secretary of State. (1992). Ballot Propositions, General Election.

Copi, I. M. (1978). Introduction to Logic. Fifth edition. New York: Macmillan.

Copi, I. M. and Burgess-Jackson, K. (1996). Informal Logic. Third edition. Upper Saddle

River, NJ: Prentice-Hall. 
Copi, I. M. and Cohen, C. (1990). Introduction to Logic. Eighth edition. New York: Macmillan.

Donn, M. (1990). "Help in Finding Missing Premises," Teaching Philosophy vol. 13, no. 2 , pp. $160-1$.

Ennis, R. (1982). "Identifying Implicit Assumptions," Synthese 51, pp. 61-86.

Fogelin, R. (1982). Understanding Arguments: An Introduction to Informal Logic. Second edition. New York: Harcourt, Brace, Javonovich.

Freeman, J. (1991). Dialectics and the Macrostructure of Arguments: A Theory of Argument Structure. Amsterdam: Mouton de Gruyter.

Govier, T. (1987). Problems in Argument Analysis and Evaluation. Dordrecht: Fortis.

Hacking, I. (2001). An Introduction to Probability and Inductive Logic. Cambridge: Cambridge University Press.

Hatcher, D. (1999). "Why Formal Logic Is Essential for Critical Thinking," Informal Logic vol. 19, no 1, p. 77-89.

Hempel, C. G. (1966). Philosophy of Natural Science. Englewood Cliffs, NJ: PrenticeHall.

Hendrickson, S. (1995). Glamour (March).

Hurley, P. J. (1991). A Concise Introduction to Logic. Fourth edition. Belmont, CA: Wadsworth.

Johnson, R. H. (1996). The Rise of Informal Logic. Newport News, VA: Vale Press.

Kelley, D. (1998). The Art of Reasoning. New York, N.Y.: W. W. Norton \& Co. Inc.

Kukla, A. (1993). "Laudan, Leplin, Empirical Equivalence and Underdetermination," Analysis 53, 8-16.

Malone, M. and Sherry, D. (1999). "Diagramming Criticisms of Explanations," at the Central Division Meetings, American Philosophical Association.

Malone, M. and Sherry, D. (1998). Inference and Implication. Dubuque, IA: Kendall/ Hunt.

Moore, B. N. and Parker, R. (1995). Critical Thinking. Fourth Edition. Mountain View, CA: Mayfield.

Norris, S. and Ennis, R. (1989). Evaluating Critical Thinking. Pacific Grove, CA: Midwest Publications.

New York Times. (1994). "The Science Upgrade Proves Steep," Sept. 1, p. A26.

Plumer, G. (1999). "Necessary Assumptions," Informal Logic vol. 19, no. 1, 41-61.

Rowen, L. (1984). "“Convergent' and 'Linked' Reasons Revisited," Newsletter on Teaching Philosophy vol. 4, no. 5.

Scriven, M. (1976). Reasoning. New York: McGraw-Hill.

Skinner, B. J. and S. C. Porter. (1992). "Breaks in the Stratigraphic Record," The Dynamic Earth. Second edition. New York: Wiley.

Tarski, A. (1956, first published in 1936). Logic, Semantics, Metamathematics, Woodger (ed.). Oxford: OUP.

Thomas, S. (1981). Practical Reasoning in Natural Language. Englewood Cliffs, NJ: Prentice-Hall. 
Walton, D. (1996). Argument Structure: A Pragmatic Approach. Toronto: University of Toronto Press.

Wason, P. and Johnson-Laird, P. (1968). Thinking and Reasoning. Penguin Books.

Will, G. F. (1995). Arizona Daily Sun, March 29, p. 6.

Yanal, R. J. (1991). “Dependent and Independent Reasons," Informal Logic 13:.3, 137 44.

Michael E. Malone Department of Philosophy Northern Arizona University Flagstaff, AZ 86011

michael.malone@nau.edu 